\title{
Source apportionment and carcinogenic risk assessment of passive air sampler-derived PAHs and PCBs in a heavily industrialized region
}

\author{
Banu Cetin ${ }^{\mathrm{a}, *}$, Sema Yurdakul ${ }^{\mathrm{b}}$, Elif Gungormus ${ }^{\mathrm{c}}$, Fatma Ozturk ${ }^{\mathrm{d}}$, Sait C. Sofuoglu ${ }^{\mathrm{e}}$ \\ a Environmental Engineering Department, Gebze Technical University (GTU), 41400 Gebze, Kocaeli, Turkey \\ b Environmental Engineering Department, Suleyman Demirel University, 32260 Isparta, Turkey \\ c Department of Chemical Engineering, Izmir Institute of Technology, 35430, Gulbahce, Urla, Izmir, Turkey \\ d Environmental Engineering Department, Abant Izzet Baysal University (AIBU), 14030 Bolu, Turkey \\ e Department of Environmental Engineering, Izmir Institute of Technology, 35430, Gulbahce, Urla, Izmir, Turkey
}

\section{H I G H L I G H T S}

- Possible sources and carcinogenic health risks of PAHs and PCBs were investigated in Dilovasi.

- Major anthropogenic origins; traffic, combustion, iron-steel production, were revealed.

- Probabilistic assessment showed that a majority of population face significant health risks.
G R A P H I C A L A B S T R A C T

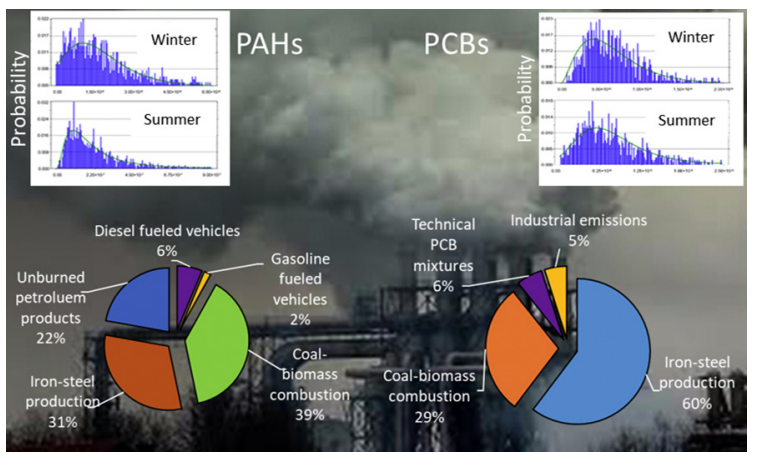

\section{A B S T R A C T}

Cancer has become the primary reason of deaths in Dilovasi probably due to its location with unique topography under the influence of heavy industrialization and traffic. In this study, possible sources and carcinogenic health risks of PAHs and PCBs were investigated in Dilovasi region by Positive Matrix Factorization (PMF) and the USEPA approach, respectively. PAHs and PCBs were measured monthly for a whole year at 23 sampling sites using PUF disk passive samplers. Average ambient air concentrations were found as $285 \pm 431 \mathrm{ng} / \mathrm{m}^{3}$ and $4152 \pm$ $6072 \mathrm{pg} / \mathrm{m}^{3}$, for $\Sigma_{15} \mathrm{PAH}$ and $\Sigma_{41} \mathrm{PCB}$, respectively. PAH concentrations increased with decreasing temperature especially at urban sites, indicating the impact of residential heating in addition to industrial activities and traffic. On the other hand, PCB concentrations mostly increased with temperature probably due to enhanced volatilization from their sources. Possible sources of PAHs were found as emissions of diesel and gasoline vehicles, biomass and coal combustion, iron and steel industry, and unburned petroleum/petroleum products, whereas iron-steel production, coal and biomass burning, technical PCB mixtures, and industrial emissions were identified for PCBs. The mean carcinogenic risk associated with inhalation exposure to PAHs and PCBs were estimated to be $>10^{-6}$ and $>10^{-5}$, respectively, at all sampling points, while the 95th percentile was $>10^{-5}$ at 15 of 23 and $>10^{-4}$ at 8 of 23 sampling locations, respectively. Probabilistic assessment showed, especially for PCBs, that a majority of Dilovasi population face significant health risks. The higher risks due to PCBs further indicated that PCBs and possibly other pollutants originating from the same sources such as PBDEs and PCNs may be an important issue for the region.

(c) 2018 Elsevier B.V. All rights reserved.

\footnotetext{
* Corresponding author.

E-mail address: bcetin@gtu.edu.tr (B. Cetin).
} 


\section{Introduction}

Dilovasi, a district of Kocaeli City, is a heavily industrialized region in Turkey with many companies working in different sectors next to two motorways, many seaports, and railway lines. Eighty of the 500 largest manufacturing companies in Turkey are located in the industrial regions of Kocaeli. They could be classified into various sectors, which are food, wood, paper, chemical, pharmaceutical, rubber, plastic, cement, metal, and coke coals and refined petroleum products (KSO, 2016). In Dilovasi district, with a population of $>50,000$, the residential areas are located within these potential air pollutant emitters. Thus, air pollution problem threatens public health and cancer has become the primary reason of deaths in the region (Arslan et al., 2013). Moreover, its unique bowllike topography has additional adverse impacts on air quality of the district. In parallel with the inversion, decrease of dispersion and lower mixing height were frequently observed in the region (Cetin et al., 2017a).

Polycyclic aromatic hydrocarbons (PAHs) and polychlorinated biphenyls (PCBs) are known as persistent, possible toxic and carcinogenic/mutagenic pollutants. The major anthropogenic sources of PAHs were reported as motor vehicle exhaust, coke and aluminum production, coal gasification and liquefying plants, carbon black, coal-tar pitch and asphalt production, catalytic cracking towers and related activities in petroleum refineries (Ravindra and Grieken, 2008; Wang et al., 2015; Wild and Jones, 1995). Benzo(a)pyrene is listed as a human carcinogen by the International Agency for Research on Cancer (IARC) and other PAHs are converted to its equivalents to estimate risks. Primary sources of PCBs are the industrial by-product of thermal processes such as uncontrolled waste incineration, metal smelting and refining processes, thermal power generation, cement kilns, the burning of wood and other biomass fuels used in transport vehicles with combustion or industrial processes such as iron and steel production, paper manufacturing processes, and chlorine bleaching of pulp and paper (Acara, 2006; Breivik et al., 2002). In air quality management, source identification is an important step for better understanding and controlling the pollutants. Positive Matrix Factorization (PMF) is a receptor model that is widely used to identify the sources of persistent organic pollutants (POPs). Last version of PMF (EPA PMF v5.0 program) enables users to successfully handle multiple site data (USEPA, 2014) obtained by means of passive sampling. Recently, Cetin (2016) applied Factor Analysis (FA) to identify the sources of PAHs and PCBs in Dilovasi soil, while Chemical Mass Balance (CMB) was performed for sediment PCBs by Gedik et al. (2010) in Izmit Bay including Dil Creek located in Dilovasi. On the other hand, health risks of PAHs were estimated by Gaga et al. (2012) at only one point in City of Kocaeli but far from Dilovasi, and based on unit risk. Therefore, to date, there is not any study on sources or carcinogenic health risks of atmospheric PAHs and PCBs in Dilovasi region, a unique place where such large and variety of sources, and residential area are conglomerated in a relatively small area. Considering the population living in this polluted area, it is vital to monitor and control the POP contamination, and to assess health risks and possible sources of pollutants for creating a reliable basis for risk management and decision-making by the local government. With these purposes, the possible sources of passive sampler-derived PAHs and PCBs were analyzed using PMF and carcinogenic health risks associated with inhalation exposure were assessed.

\section{Material and methods}

\subsection{Sampling program, preparation, and analysis}

The ambient air sampling was conducted monthly using polyurethane foam (PUF) disks for a whole year at 23 sites from February 2015 to February 2016. The samples were collected each month (12 samples for each site) and the average sampling duration was 30.5 days. Totally, 276 samples were collected and analyzed for PAHs and PCBs. During the sampling period, the average ambient air temperatures fluctuated from 5.1 to $26.7^{\circ} \mathrm{C}$, and generally northerly and southwesterly winds were observed in the region. Before sampling, all the PUF disks were spiked with depuration compounds (DCs) $\left({ }^{13} \mathrm{C}-\mathrm{PCB} 3\right.$, ${ }^{13} \mathrm{C}-\mathrm{PCB} 9,{ }^{13} \mathrm{C}-\mathrm{PCB} 15$, PCB 30, PCB 107, and PCB 198) and they were stored in the freezer until field study, about 1 week. After sampling, PUF disks were spiked with surrogate standards and were extracted with equal volumes of acetone-hexane mixture for $24 \mathrm{~h}$ in Soxhlet system. After extraction, sampling preparation procedure was carried out with various steps in order of solvent exchange and concentrating using rotary evaporator, clean-up and fractionation with aluminasilicic acid column, and final concentrating to $1 \mathrm{ml}$ with a gentle stream of $\mathrm{N}_{2}$. The details of procedure can be found in Supplementary Material (SM1).

USEPA priority PAHs and 41 PCBs (please see SM1 for details of target compounds) were analyzed with Agilent $6890 \mathrm{~N}$ gas chromatograph (GC) equipped with a mass selective detector (Agilent 5975 inert MSD) in electron impact ionization mode. An HP-5 ms ( $30 \mathrm{~m}, 0.25 \mathrm{~mm}, 0.25$ $\mu \mathrm{m})$ capillary column was utilized for the separation of chemicals in selected ion-monitoring mode (SIM). Chemicals were identified based on their retention times, target and qualifier ions. Further details can be found elsewhere (Cetin et al., 2017a, 2017b; Cetin et al., 2007; Cetin, 2016). The average recoveries of the surrogate standards were $69 \pm$ 10\% (acenaphthene-d10), $74 \pm 12 \%$ (phenanthrene-d10), $77 \pm 16 \%$ (chrysene-d12), $69 \pm 13 \%$ (perylene-d12), $94 \pm 13 \%$ (PCB-14), 90 $\pm 11 \%$ (PCB-65) and $87 \pm 14 \%$ (PCB-166). Due to low recoveries of naphthalene, its concentrations are not reported herein. The instrumental detection limits were determined by linear extrapolation from the lowest standard in the calibration curve and the area of a peak that has a signal/noise ratio of 3 . The quantifiable amounts of the PCB and PAH were found to be 0.10 and $0.15 \mathrm{pg}$ for $1 \mu \mathrm{l}$ injection, respectively. In addition, blanks were analyzed along with the samples, and the results were reported as blank corrected. For the estimation of the method detection limit (ng), three times the standard deviation was added to the mean blank mass ( $\mathrm{MDL}=$ mean blank value $+3 \mathrm{SD}$ ).

The effective sampling air volumes, $V_{\text {air }}\left(\mathrm{m}^{3}\right)$ were determined using the equation developed by Shoeib and Harner (2002) and the sampling rates, $\mathrm{R}\left(\mathrm{m}^{3} \mathrm{day}^{-1}\right)$ were calculated using the recovery of depuration compounds (Shoeib and Harner, 2002). For all the sampling periods, the average sampling rate was found between 1.75 and $4.07 \mathrm{~m}^{3}$ day $^{-1}$ $\left(A V G \pm S D ; 2.76 \pm 0.47 \mathrm{~m}^{3}\right.$ day $\left.^{-1}\right)$. Details of the calculation of ambient air concentrations can be found in SM2 and was reported by Cetin et al. (2017a).

\subsection{Positive Matrix Factorization (PMF)}

EPA PMF v5.0 program, developed by the US Environmental Protection Agency which enables users to handle multiple site data, was used to infer on the sources of PAHs and PCBs measured in the Dilovasi atmosphere. Two types of data sets (input parameters) belonging to the measured pollutants; concentration and uncertainty must be entered into the model. Before applying PMF analysis, the dataset of measured pollutant concentrations was examined, and both the pollutants and samples with $<80 \%$ occupancy were removed from the dataset.

The methodology developed by Polissar et al. (2001) was followed for the calculation of the uncertainty of each pollutant. Accordingly, values below detection limit were replaced with the half of the detection limit values. For the uncertainty, the values above the detection limit were replaced with "the value x $0.05+$ detection limit" whereas the values below the detection limit were replaced with $5 / 6$ of the detection limit. Concentration values of the missing data were replaced with their geometric means and their accompanying uncertainties were replaced with four times of their geometric means. The PAH dataset consisted of 89 samples $\times 15$ compounds while the PCB dataset consisted of 90 samples $\times 31$ compounds, because seasonal average values were used for the analysis. According to the model results, both 
the $\mathrm{Q}$ (robust) and $\mathrm{Q}$ (true) values meet $50 \%$ of the $\mathrm{Q}$ (theoretical) value calculated for both compound groups. In addition, the model was run 20 times for each PAH and PCB data set, and all modeled results were converged. For PAHs and PCBs, the Q (robust) value was found to be approximately $1 \%$ and $1.2 \%$ of $\mathrm{Q}$ (true), respectively.

In this study, to identify optimum factor numbers, the relationship between the modeled and measured pollutant concentrations were also calculated and found to be higher than 0.95 for PAHs and 0.90 for PCBs, except for PCB-156, $-169,-170,-183$ and -206 . During the analysis, all of the PAH compounds were selected as strong. However, as $\mathrm{R}^{2}$ of PCB-156, $-169,-170,-183$, and -206 were $<0.90$ but higher than 0.78 , they were chosen to be weak, and scaled residues of $>99 \%$ of all pollutants were found to be between -2 and +2 .

After the identification of the optimum factor numbers, Fpeak values between -2 and +2 have also been investigated as Fpeak is one of the most important parameters affecting autocorrelation between the factors. Accordingly, the model Fpeak value was taken as zero for both PAHs and PCBs.

\subsection{Exposure and risk assessment}

Exposure via inhalation route at 23 sampling locations was estimated by calculating chronic daily intake (CDI, Eq. (1)) levels for three groups of the target pollutants, i.e. PAHs, dioxin-like PCBs, and nondioxin-like PCBs (USEPA, 2011).

$\sum_{j}^{J} C D I=\frac{C_{j} \times I R \times E D \times E F}{B W \times A T}$

where $\mathrm{C}_{\mathrm{j}}$ is the BaP equivalents $\left(\mathrm{BaP}_{\mathrm{eq}}\right.$ ) for each PAH compound concentration $\left(\mathrm{ng} / \mathrm{m}^{3}\right)$ or the concentration of 2,3,7,8-tetrachlorodibenzo-pdioxin equivalents for each dioxin-like PCB congener $\left(\mathrm{pg} / \mathrm{m}^{3}\right)$ or concentration of each non-dioxin like PCB congener $\left(\mathrm{pg} / \mathrm{m}^{3}\right)$, IR is inhalation rate $\left(\mathrm{m}^{3} / \mathrm{day}\right), \mathrm{ED}$ is exposure duration ( $\left.\mathrm{yr}\right), \mathrm{EF}$ is exposure frequency (days/yr), BW is body weight $(\mathrm{kg})$, and AT is averaging time that is assumed as lifetime (25,550 days) in carcinogenic risk assessment. Toxic equivalence factor (TEF) values proposed by Nisbet and LaGoy (1992) and USEPA (2010), listed in Table S1, were used to calculate $\mathrm{BaP}$ and dioxin equivalent concentrations. Targeted dioxin-like PCBs were PCB 105, 118, 156, and 169. CDI levels were calculated by considering an exposure duration throughout lifetime ( $E D=70 \mathrm{yr}$ ). EF was used as 90 and 365 days/yr in the calculation of seasonal and annual CDIs. Time budgets based on the five groups of activities (rest, sedentary, light, moderate, and heavy activities), listed in the Exposure Factors Handbook (USEPA, 1997), were constructed from the administered questionnaires for different cities in Turkey by Kavcar et al. (2006), Yllmaz Civan (2010), Gungormus et al. (2014), and Yllmaz Civan et al. (2015). They reported overall IR and BW probability distributions. Location, number of participants, IR and BW distributions in each study are given in the SM, Table S2. Joint probability distributions of the above literature-reported IR and BW distributions was constructed as better descriptors of Turkish people to be employed in this study: extreme value distribution (mode $=17.86$ and scale $=4.71$ ) for IR and beta distribution (alpha $=12.76$, beta $=8.15$, and scale $=$ 111.15) for BW. The mean, 5th and 95th percentile values of the fitted distribution was used along with the mean, 5th and 95th percentile values of measured concentrations to calculate a set of CDI point estimates for each sampling point. The carcinogenic risk associated with exposure to the targeted compounds by inhalation route was calculated using Eq. (2) (USEPA, 1996; USEPA, 2005).

$R=C D I \times S F$

where $\mathrm{R}$ is the carcinogenic risk, $\mathrm{SF}$ is the slope factor. The SF values for $\mathrm{BaP}$, dioxin, and nondioxin-like PCBs were reported as 3.9, 150,000, and 2 ( $\mathrm{mg} / \mathrm{kg} /$ day $)^{-1}$, respectively (CalEPA, 2015; USEPA, 2007). The cancer risk for dioxin-like PCBs and nondioxin-like PCBs were estimated separately, then summed to estimate cancer risk for $\Sigma_{41}$ PCBs.

In addition to the point estimates at each sampling point, a population exposure-risk assessment conducted for Dilovasi by Monte Carlo simulation using Crystal Ball software (v 4.0e). Pollutant concentrations measured at the 23 sampling points were pooled and fitted with probability distributions for this purpose in addition to the IR and BW. The Monte Carlo simulation is repetitive calculation of an equation or a model using randomly selected values for each variable with a defined probability distribution based on statistical sampling techniques. Simulation results in a large number of output values that represent the population, which may also be fitted with a probability distribution. In this study, the model output is carcinogenic risk, and number of trials was 10,000. Beta, exponential, gamma, normal, lognormal, logistic, pareto, and Weibull were the candidate distributions. The best fitting distribution was chosen based on KolmogorovSmirnov (KS) and Anderson-Darling (AD) tests. An uncertainty analysis was conducted using the bootstrap method with 200 simulations of 1000 trials each.

\section{Results and discussion}

\section{1. $P A H$ and $P C B$ concentrations}

Atmospheric concentrations of PAHs and PCBs were previously reported by Cetin et al. (2017a). Briefly, average ambient air concentrations were found as $285 \pm 431 \mathrm{ng} / \mathrm{m}^{3}$ and $4152 \pm 6072 \mathrm{pg} / \mathrm{m}^{3}$, for $\Sigma_{15} \mathrm{PAH}$ and $\Sigma_{41} \mathrm{PCB}$, respectively. Apart from industrial activities and traffic, seasonal trends of $\mathrm{PAH}$ concentrations reflect the contribution of residential heating with higher values obtained in winter season. PHE, FL, and PY have greater impact on $\Sigma_{15} \mathrm{PAH}$ concentrations with $42 \pm 6,18 \pm 3$ and $15 \pm 3 \%$ contributions, respectively. The seasonal trend of PCBs was found to be the opposite of PAHs with largely increased with temperature, probably due to enhanced volatilization from their sources. Especially in urban/industrial regions, extremely high PCB concentrations were observed in summer. Low molecular weight congeners including PCB-28, $-18,-31$, and -33 had higher contributions to $\Sigma_{41}$ PCB concentrations. In order to better evaluate and determine the variations of target compounds, the sampling region was characterized as industrial/urban $(10,11,12,13,14,22,23)$, urban (1, $5,9,15,16,17,18,19$, and 20), suburban (6, 7 and 8 ), and rural (sampling sites 2, 3 and 4). Accordingly, the spatial distributions of PCBs were found to be more apparent than those for PAHs, and obtained as rural $<$ suburban $<$ urban $<$ industrial/urban.

\section{2. $P M F$}

In Dilovasi, there are $>185$ companies in 45 different sectors such as iron and steel, glass, paint, wood, and chemical industries that are clustered in five organized industrial zones. Moreover, coal is used for domestic heating in the district and causes significant air pollution problems in winters. Thus, to apportion the sources of PAHs and PCBs in the Dilovasi atmosphere, PMF was applied to the dataset.

In this study, 5 and 4 sources were obtained for ambient PAH and PCBs in Dilovasi, respectively. The explained variations of these sources, the contributions of pollutants on each factor, and the temporal variation of these contributions were examined and compared with similar studies conducted in the literature. Accordingly, the factors (sources) obtained as a result of the PMF study were identified.

The sources of the measured PAH compounds is depicted in Fig. 1. Biomass and coal combustion was found to be the most significant potential PAH contributor ( $39 \%$ ) to the Dilovasi atmosphere, and it was followed by the iron and steel industry $(\sim 31 \%)$, unburned petroleum products ( $22 \%)$, diesel vehicles $(\sim 6 \%)$ and gasoline vehicles $(\sim 2 \%)$. A fairly good correlation was obtained between the modeled and the 

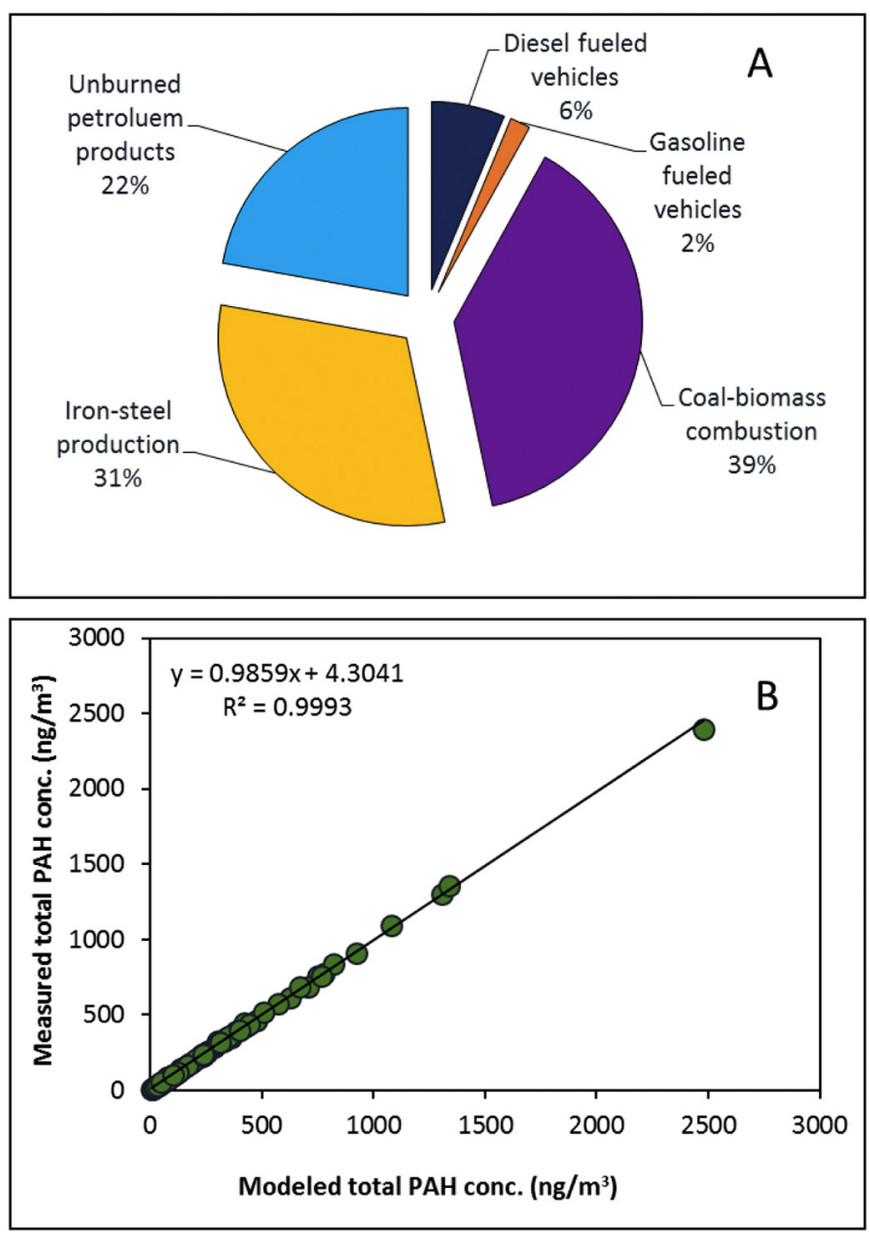

Fig. 1. (A) Contribution of the identified sources to the total PAH concentration and (B) the relation between modeled and measured total PAH concentrations.

actual measurement results. The source profiles of measured PAH concentrations are given in Fig. 2.

The first two factors were found to be related with traffic. The first factor explaining $6.3 \%$ of the total $\mathrm{PAH}$ concentration had high loadings of ACT, CHR, BbF and BkF, while ACY, PY, BaA, BaP, and BghiP had moderate contributions on this factor. It was stated in the literature that CHR was related to diesel vehicle exhaust and $\mathrm{BkF}$ was a compound that shows traffic emissions (Rajput and Lakhani, 2010), and high molecular weight PAHs such as BghiP and DahA were the dominant PAHs in vehicle exhausts (MotelayMassei et al., 2007; Amador-Munoz et al., 2010; Li et al., 2011). IcdP, BghiP, and BaP are the typical oil combustion tracers in the environment (Sadiktsis et al., 2012) and PY is a diesel indicator which is used to differentiate diesel from gasoline vehicle emissions (Alsberg et al., 1989; Larsen and Baker, 2003). Although the source strength for these two factors were low in summer when traffic flow low due to holiday season, similar contributions were obtained for the other seasons. Therefore, it was indicated that the first factor was attributed to emissions from diesel fueled vehicles, and the second factor, which accounts for $1.73 \%$ of the total concentration, was attributed to emissions from gasoline fueled vehicles.

The third factor was found to be rich in terms of PHE, FL, PY, and CHR. Approximately $45 \%$ of the PHE was explained on this factor. In various studies conducted in the literature, the high contribution of PHE was explained by coal combustion or unburned gasoline originating from vehicles (Kavouras et al., 2001; Zuo et al., 2007). FL and PY were mostly used as indicators of emissions from coal combustion. CHR was also used as a sign of domestic coal combustion, coke oven and biomass/coal-derived emissions (Aydın et al., 2014). The seasonality of source contributions supported these arguments because the highest source contribution was observed for the winter months for this factor (Fig. 3). Therefore, Factor 3, which accounts for $38.68 \%$ of the total PAH concentration, was attributed to emissions resulting from biomass and coal combustion.

ACY, ANT, and BaA were found to be highly loaded on Factor 4. On the other hand, FLN, PY, PHE, DahA had lower influence on this factor. Odabasi et al. (2009) and Aydin et al. (2014) have reported that ACY, ANT, FLN, PHE, PY, and BaA were emitted to the atmosphere during iron and steel production from waste metal. Furthermore, high loading of ANT (50\%), followed by moderate loading of BaA and PY on this factor suggests that Factor 4 was related with iron and steel industry (Jang et al., 2013). The last factor was dominated by ACT and FL, and moderate loading of PHE, ANT, and IcdP. ACT and FL are major indicators for unburned petroleum emissions. PHE is also an indicator of unburned petroleum products and coal burning (Aydın et al., 2014). Furthermore, the highest source contribution was observed in winter and autumn months for this factor, with clear seasonal variation. Therefore, observations of the highest source contributions during the cold seasons indicate combustion as a source. So, this factor was attributed to emissions from unburned petroleum products.

In this study, PMF analysis revealed 4 factors for the measured PCBs (Fig. 4). Iron and steel production was found to be the most important PCB source with $\sim 60 \%$ contribution to total PCB concentration in Dilovasi atmosphere. Iron and steel production was followed by coal and biomass burning ( $29 \%)$, technical PCB mixtures ( $6 \%)$, and industrial emissions $(\sim 4 \%)$. A fairly good correlation was obtained between the modeled values and actual measurements. The source contributions of these factors are given in Fig. 5.

The first factor was dominated with PCB-118, -128, -132, -138, -149, -180 , and -170 . Domestic coal and wood combustion emissions were found to be responsible for the PCB $-22,-28 / 31,-41 / 64,-49,-118$, -110 , and $-153 / 132$ (Lee et al., 2005). Furthermore, Kim et al. (2004) reported that PCB-128, -170, -171, and 206 were major indicators for coal combustion. As a result, this factor has been determined as coal-biomass burning. The second factor was mostly loaded with moderate and heavy molecular weight PCBs (such as PCB-151, -156, -158, -169, -170, -180, -183 , and -187 ) which explained $5.78 \%$ of the total variance. These species are the main components of technical PCB mixtures such as Arochlor 1254, Arochlor 1260, and Kaneklor 600 (Takasuga et al., 2006; Jin et al., 2012). Seasonal variation of factor 2 scores showed higher values in summer. This pattern suggests an evaporative source for factor 2. Accordingly, this factor was identified as technical PCB mixtures. The third factor was dominated by low molecular weight PCBs (PCB-17, -18, -28, -31, -44, -49, -52, -70, -74, -82, -87, -95, -99, -101, and -110 ) that explained $60 \%$ of the total variance. Previously Odabasi et al. (2009) and Aydın et al. (2014) reported that the iron and steel plant emissions were dominated by the low molecular weight PCBs, and PCB $-18,-28,-31$, and -33 were tracers for iron and steel production. Similar to the second factor, the highest source contribution was observed in summer for factor 3 . Therefore, this factor was attributed to iron and steel production. The last factor was dominated by heavy molecular weight PCBs such as PCB-158, 169, -170, -180, and -206. It included a high loading by PCB-206 that contributed $90 \%$ to the total variance. PCB -206 and -209 are believed to form during the production of various pigments (azo and phthalocyanine pigments) (Hu and Hornbuckle, 2010; Davies and Delistraty, 2016). Furthermore, high chlorinated PCBs (PCB-206, PCB-208, and PCB-209) are also used in the production of titanium dioxide (Davies and Delistraty, 2016). Although the seasonal variation of factor 4 scores showed higher values in winter, a clear seasonal variation could not be observed for this factor. This may be due to the high intensity of industrial activity in the district. Hence, this factor was categorized as mainly associated with industrial activities. 

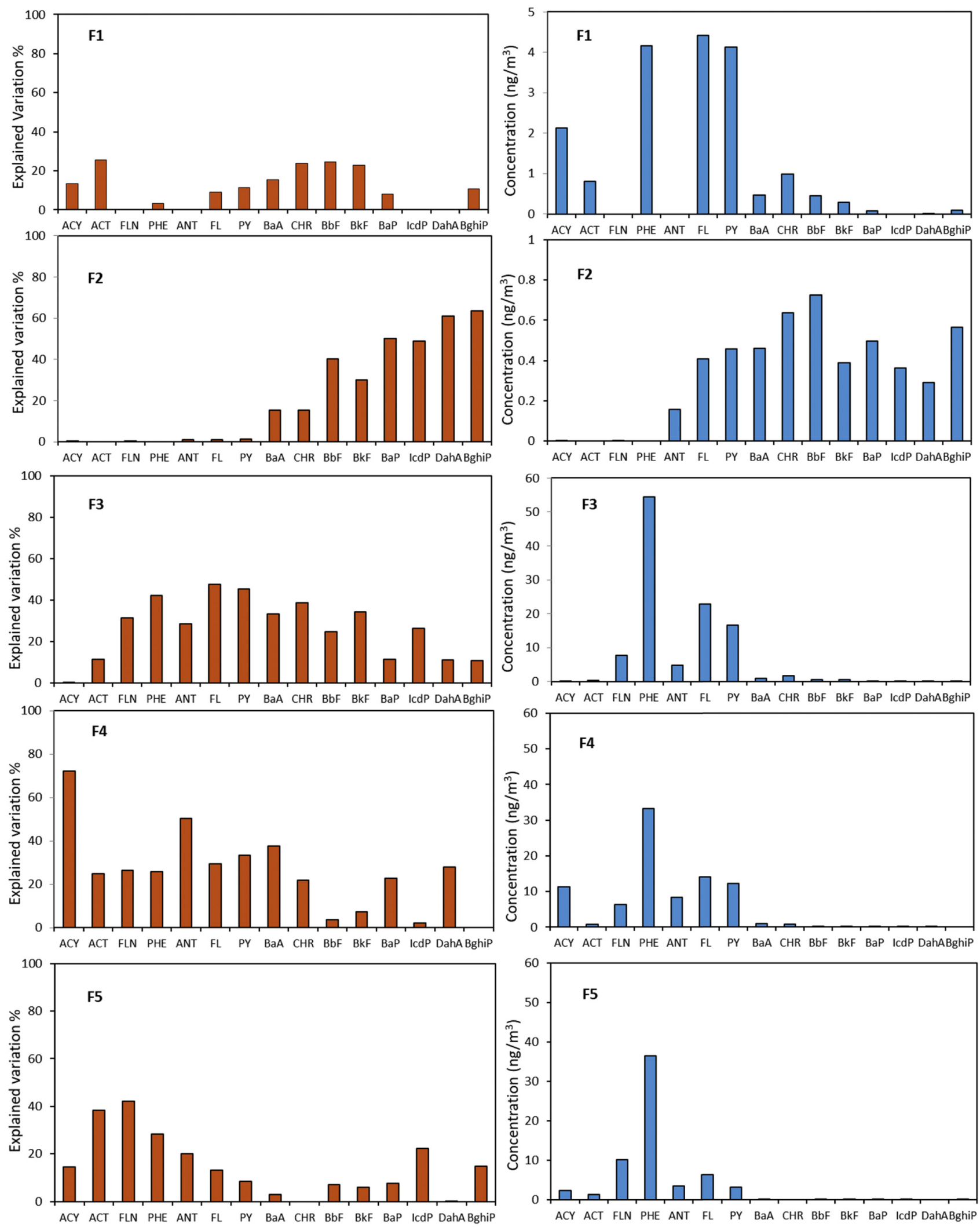

Fig. 2. The source profiles of measured PAH concentrations.

Previously, local soil was also shown as a source especially for volatile PCBs and PAHs (Cetin et al., 2007, 2017a; Kaya et al., 2012). Thus, soil should be considered as sources for volatile PCBs and PAHs, especially in summer. Source/sink potency of soil for PCBs and PAHs in
Dilovasi was reported in Cetin et al. (2017a). Generally, soil behaves as a secondary source for the emission of PAHs into the atmosphere in the industrial and urban areas. Besides, PCBs were found to be generally deposited to soil except some low chlorinated PCBs obtained from the 


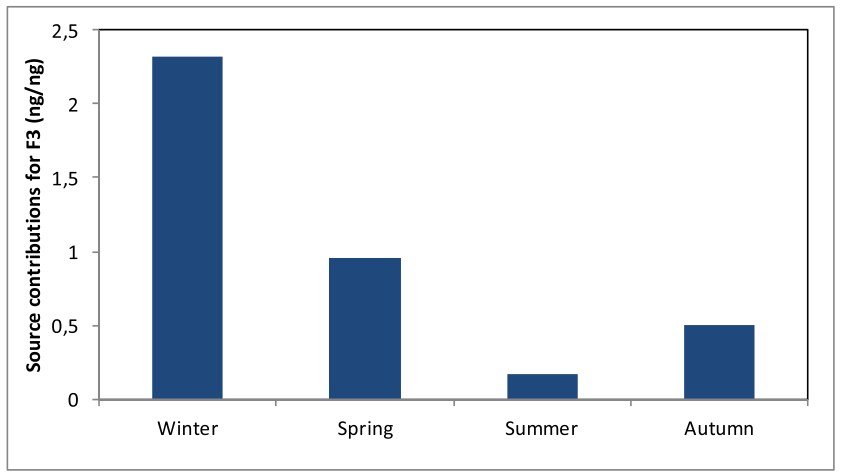

Fig. 3. Seasonal variation of source contributions to total PAH concentration for Factor 3.

industrial/urban sites in summer, probably due to significant ongoing sources in the region.

\subsection{Exposure - risk assessment}

\subsubsection{Point estimates, spatial and seasonal variation}

Point estimates of exposure to PAHs and PCBs, and associated carcinogenic risks were calculated based on concentrations measured over a one-year period at each sampling location except sampling point 21
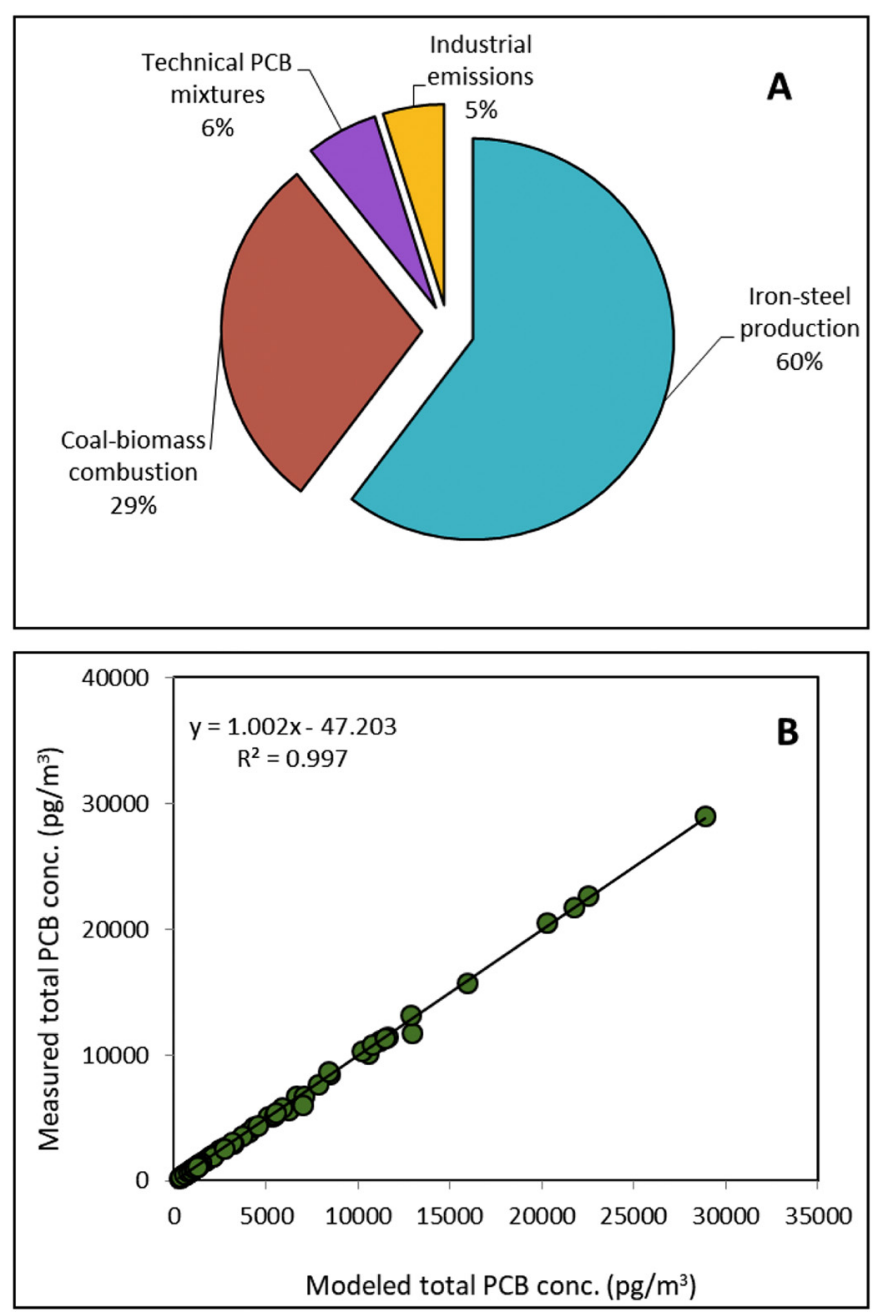

Fig. 4. (A) Contribution of the identified sources to the total $\mathrm{PCB}$ concentration and (B) the relation between modeled and measured total PCB concentrations. where air samples could only be collected during spring and summer. A set of estimates, 5th percentile, mean, and 95th percentiles were made. Carcinogenic risks based on the annual mean concentrations of $\Sigma_{15}$ PAHs and $\Sigma_{41}$ PCBs are plotted in Figs. 6 and 7 to show spatial variation (depicted with sizing of the circles) along with temporal variation (depicted with a color classification) in the concentrations. The temporal variation at each point was calculated using a modified coefficient of variation $(\mathrm{mCV})$. The $\mathrm{mCV}$, where 5 th to 95th percentile range is divided by the mean value, was used to display the variation in the point estimates. All of the estimated exposure and risk values for both $\Sigma_{15}$ PAHs and $\Sigma_{41}$ PCBs can be found in Tables S3 and S4.

The annual mean exposure and risk levels of $\Sigma_{15}$ PAHs ranged from $0.123 \mathrm{ng} / \mathrm{kg} /$ day at sampling site 6 to $2.121 \mathrm{ng} / \mathrm{kg} /$ day at sampling site 1 , and from $4.79 \times 10^{-7}$ at site 6 to $8.27 \times 10^{-6}$ at site 1 , respectively. The highest three exposure and risk levels were determined at sampling site 1 (urban area), 12 (industrial/urban area), and 9 (urban area). The spatial distribution for exposure and risk levels of $\Sigma_{15}$ PAHs were found in the order of rural $\approx$ suburban $<$ urban $\approx$ industrial/urban areas. Most of the targeted PAH compounds in this study are classified as Group 2B carcinogens (possible human carcinogens) by IARC. Based on various levels of animal studies, chronic exposure to PAH compounds increases the risk of lung, bladder, stomach, and skin cancer (ATSDR, 2009). One in a million chance of additional human cancer over a 70 -year lifetime $\left(10^{-6}\right)$ is generally defined as the acceptable carcinogenic risk by the USEPA. The risk levels above $10^{-6}$ indicate potential health risks. However, the acceptable level may be increased to $10^{-5}$ or $10^{-4}$, depending on the pollutant (Kavcar et al., 2009; Sofuoglu et al., 2014). The calculated mean carcinogenic risk levels of PAHs for all sampling points except sampling site 3 (rural site) and 6 (suburban site), and the calculated 95th percentile carcinogenic risk levels for all sampling points in Dilovasi were found as $>10^{-6}$ while 95th percentile was $>10^{-5}$ at 15 out 23 sampling locations in this study. Gaga et al. (2012) measured PAH concentrations at a sampling point in Kocaeli, the province in which Dilovasi is located, to investigate seasonal variations, influence of meteorological parameters, and health risk of PAHs. The lung cancer risk of people living in Kocaeli was estimated deterministically by using exposure concentration and unit risk based on human body weight of $70 \mathrm{~kg}$ and inhalation rate of $20 \mathrm{~m}^{3} /$ day. The cancer risks in the heating and non-heating periods in Kocaeli were reported as $2.92 \times 10^{-3}$ and $1.15 \times 10^{-3}$, respectively. The calculated health risks by Gaga et al. (2012) are quite greater than those in this study. Zhuo et al. (2017) investigated the occurrence, temporal variance, and sources of ambient PAHs, and health risk due to PAHs inhalation exposure in a megacity, Nanjing located in western Yangtze River Delta (YRD), China. Pointestimates were made for inhalation cancer risk. The mean risk levels for ambient BaP and 16 EPA priority PAHs were estimated as $5.6 \times 10^{-5}$ and $1.6 \times 10^{-4}$, which are greater than those in this study. It was determined that diesel vehicles and petrogenic sources have large contributions to the estimated cancer risk, among which gasoline vehicles generating highly toxic PAHs especially dibenzopyrene (which was not investigated in this study), were determined as a significant source leading to cancer risk associated with PAH exposure. Cuadras et al. (2016) collected air samples from two suburban sites, located $<1 \mathrm{~km}$ from two largest chemical complexes in the Southern Europe and the Mediterranean area, in the Tarragona region, Spain. The estimated lung cancer risk was reported in the range between $3.2 \times 10^{-5}$ and $4.3 \times 10^{-5}$, which are greater than those estimated in this study. FL, DahA, and BaP together had large contributions to the risk with $81-85 \%$. Petroleum combustion, traffic emissions, and petrogenic sources were reported as the main sources of the high exposure levels to PAHs compounds.

PCBs were not produced in Turkey and their use has been banned since 1996 . However, they are still detected in air, sediment, and soil samples collected from different locations in Turkey (Birgül 

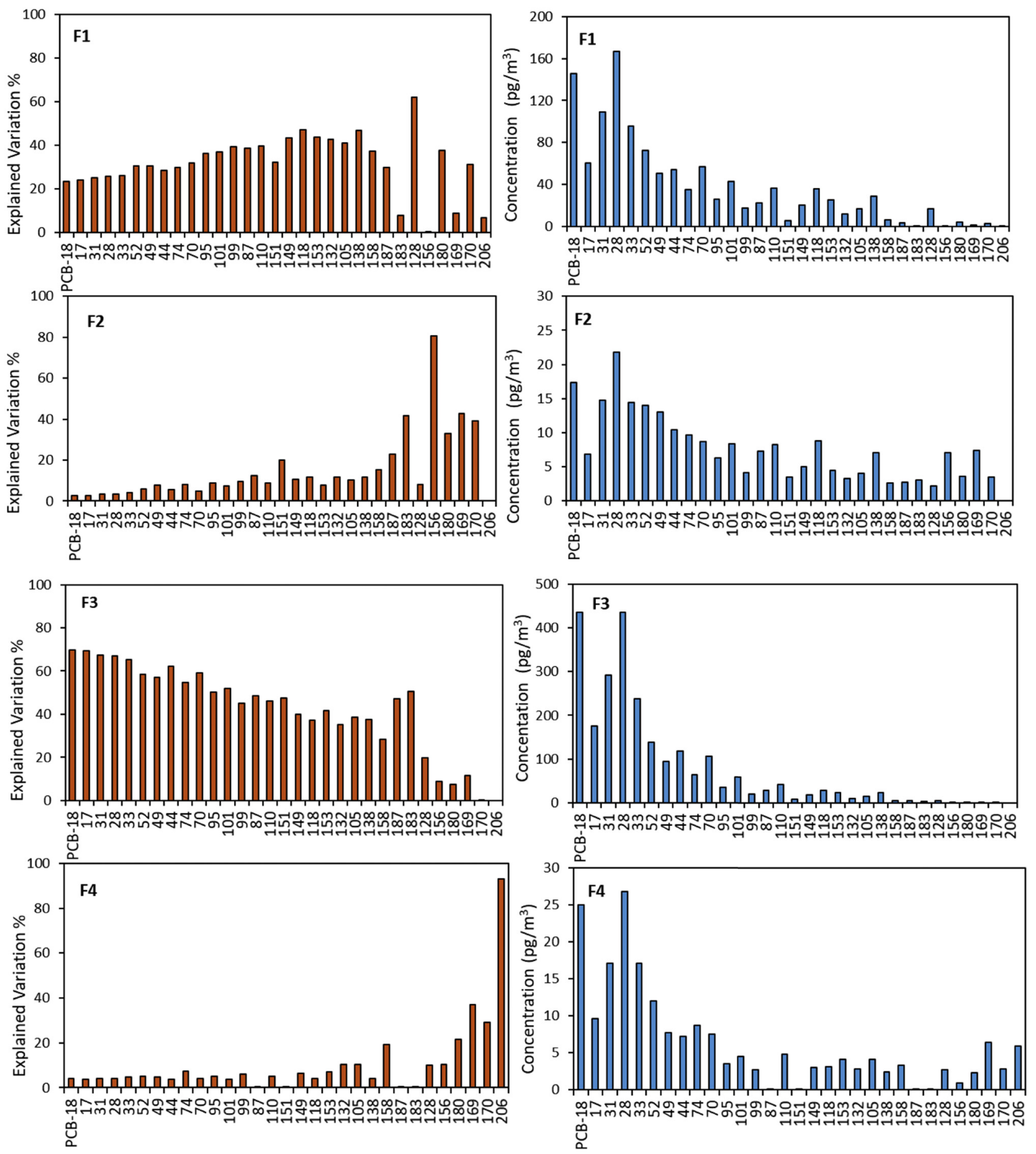

Fig. 5. The source profiles of measured PCBs concentrations.

et al., 2017; Cetin, 2016; Cetin et al., 2017b; Odabasi et al., 2017; Ogulmus et al., 2016; Ugranli et al., 2016). The annual mean exposure levels of $\Sigma_{41}$ PCBs ranged between $88 \mathrm{pg} / \mathrm{kg} /$ day (sampling site 3 ) and $3817 \mathrm{pg} / \mathrm{kg} /$ day (site 22), while the risk levels were in the range of $9.04 \times 10^{-6}$ at sampling site 3 to $5.45 \times 10^{-5}$ at sampling site 22 . The calculated mean risk levels for all sampling points were $>10^{-5}$, while they were $>10^{-4}$ at 8 out of 23 locations indicating considerable potential health risks. Types of cancer associated with exposure to PCBs are melanomas, liver, gall bladder, biliary tract, gastrointestinal tract, and brain cancer (ATSDR, 2000). The spatial distribution for $\Sigma_{41}$ PCBs was apparent as rural $<$ suburban $<$ urban $<$ industrial/urban areas. The estimated highest exposure and inhalation risk levels in industrial/urban areas can be explained with the intensity of PCB sources in these areas. There are no point estimates reported for exposure and carcinogenic risk for PCB congeners in Turkey. Several studies regarding exposure-risk levels of PCBs around the world could be found in the literature (Vilavert et al., 2014; Zhang et al., 2013). Zhang et al. (2013) collected air samples from an industrialized and urbanized area in eastern China for a year at 31 sites. All estimated inhalation risks were found $<10^{-6}$, indicating acceptable risk levels. Vilavert et al. (2014) 


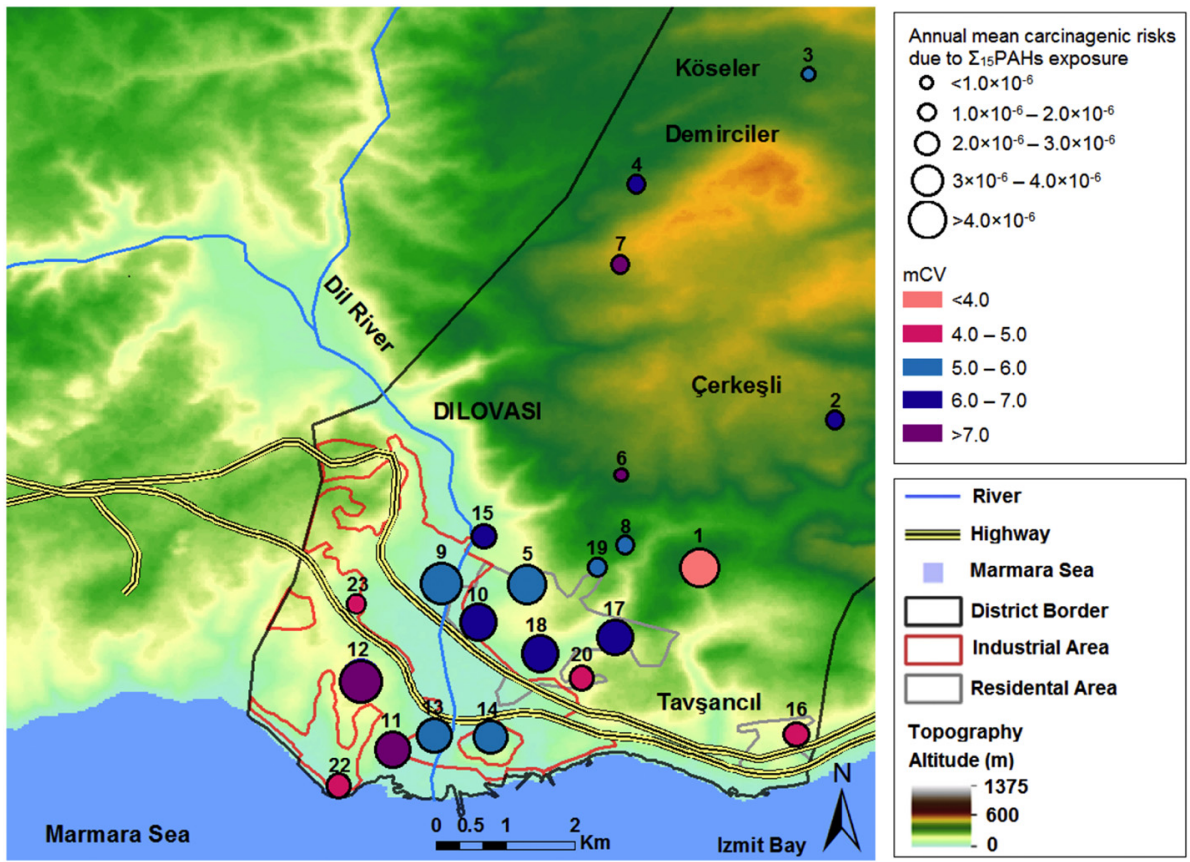

Fig. 6. Spatial and temporal variation in $\Sigma_{15} \mathrm{PAHs}$ carcinogenic risk levels.

determined PCB levels in air samples collected during 2010-2011 from Tarragona, Spain. The exposure to PCB congeners via inhalation route was estimated in the range of 6.80 to $7.59 \mathrm{pg} / \mathrm{kg} / \mathrm{day}$. The inhalation cancer risks for PCBs were reported as $<1 \times 10^{-5}$, which is the threshold level established in Spain for carcinogenic risk. The estimated risk levels in both of the studies are lower than those found in this study.

\subsubsection{Population exposure and carcinogenic risks}

Twenty-three sampling points selected in Dilovasi are located within an area not larger than $50 \mathrm{~km}^{2}$, thereby population exposure and carcinogenic risk for $\Sigma_{15}$ PAHs and $\Sigma_{41}$ PCBs were calculated by pooling the locations and considering only seasonal differences. Exposure and risks were estimated for the whole dataset (all sampling points except sampling point 21 where air samples could only be collected in summer and spring) for each season. Monte Carlo simulation was implemented to estimate population carcinogenic risks associated with inhalation exposure route. Fitted distributions for each input variable to the exposure models, the estimated exposures, and their parameter values are presented in Table S5.

The estimated mean inhalation exposure to $\Sigma_{15}$ PAHs ranged from $0.060 \mathrm{ng} / \mathrm{kg} / \mathrm{day}$ in summer to $0.424 \mathrm{ng} / \mathrm{kg} / \mathrm{day}$ in winter, while the 95th percentile exposure was from $0.151 \mathrm{ng} / \mathrm{kg} / \mathrm{day}$ in summer to

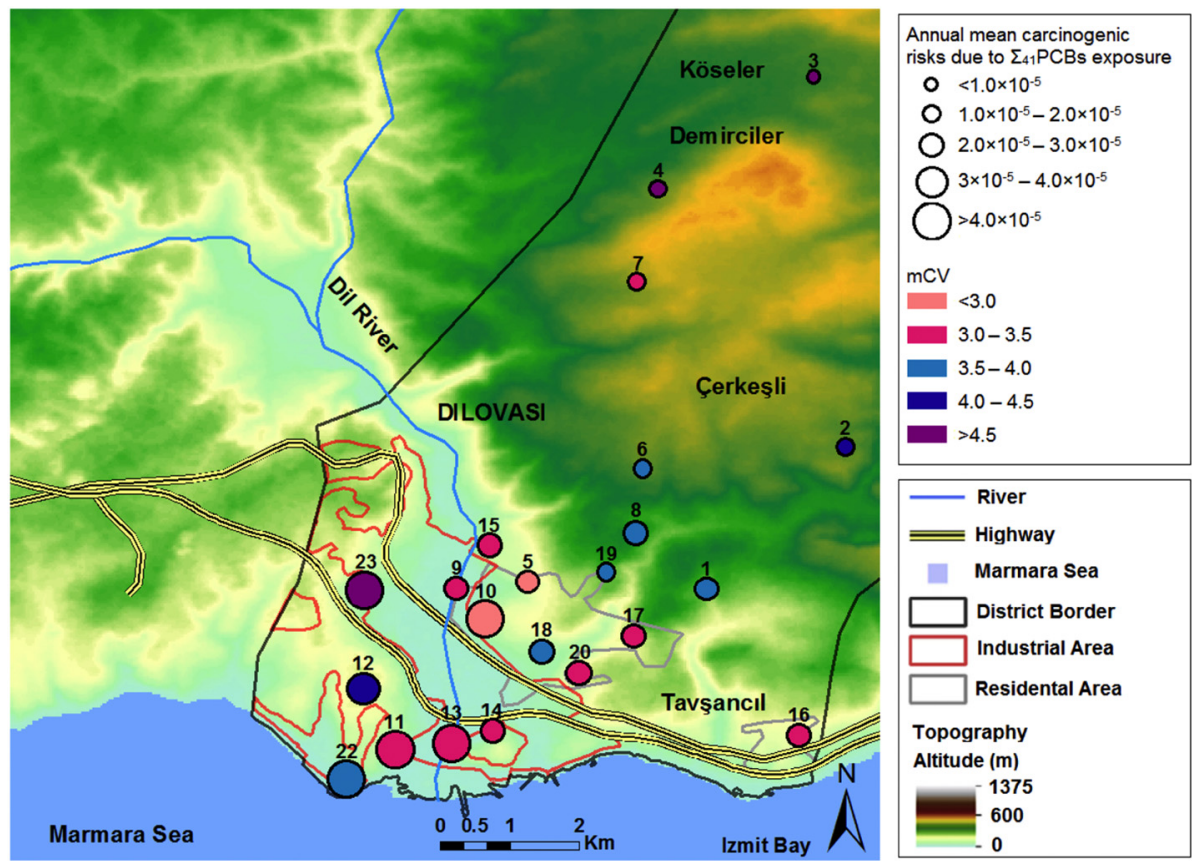

Fig. 7. Spatial and temporal variation in $\Sigma_{41}$ PCBs carcinogenic risk levels. 
Table 1

Population mean and 95th percentile inhalation exposure and risk levels for $\Sigma_{15} \mathrm{PAHs}$ and $\Sigma_{41}$ PCBs.

\begin{tabular}{llllll}
\hline & \multicolumn{2}{l}{ Mean } & & \multicolumn{2}{l}{ 95th percentile } \\
\cline { 2 - 3 } \cline { 5 - 6 } & CDI & Risk & & CDI & Risk \\
\hline$\Sigma_{15}$ PAHs $^{\text {a }}$ & & & & \\
Winter & 0.424 & $1.65 \times 10^{-6}$ & & 1.142 & $4.46 \times 10^{-6}$ \\
Spring & 0.154 & $6.00 \times 10^{-7}$ & & 0.457 & $1.78 \times 10^{-6}$ \\
Summer & 0.060 & $2.32 \times 10^{-7}$ & & 0.151 & $5.88 \times 10^{-7}$ \\
Autumn & 0.168 & $6.04 \times 10^{-7}$ & & 0.562 & $2.07 \times 10^{-6}$ \\
$\Sigma_{41}$ PCBs $^{\mathrm{b}}$ & & & & \\
Winter & 165 & $6.74 \times 10^{-6}$ & & 562 & $1.38 \times 10^{-5}$ \\
Spring & 186 & $4.90 \times 10^{-6}$ & & 628 & $1.09 \times 10^{-5}$ \\
Summer & 509 & $8.24 \times 10^{-6}$ & & 1978 & $1.98 \times 10^{-5}$ \\
Autumn & 330 & $7.07 \times 10^{-6}$ & & 1158 & $1.61 \times 10^{-5}$ \\
\hline
\end{tabular}

${ }^{\mathrm{a}} \mathrm{CDI}: \mathrm{ng} / \mathrm{kg} / \mathrm{day}$.

b $\mathrm{CDI}: \mathrm{pg} / \mathrm{kg} /$ day.

$1.142 \mathrm{ng} / \mathrm{kg} / \mathrm{day}$ in winter (Table 1 ). The seasonal variation was found in the order of summer $<$ spring $\approx$ autumn $<$ winter for $\Sigma_{15}$ PAHs. Residential heating is one of the main anthropogenic sources of PAHs. The addition of residential heating in colder seasons generally leads to an increase in the concentration of PAHs, thus an increase in exposure of $\mathrm{PAH}$ compounds by inhalation route.

The higher CDI levels in colder season compared to warmer season observed in this study is in agreement with those reported in the literature (Amarillo et al., 2017; Bulejko et al., 2016; Ugranli et al., 2016). The mean inhalation risk level for $\Sigma_{15} \mathrm{PAHs}$ were estimated below $10^{-}$ ${ }^{6}$ in all seasons, except in winter $\left(1.65 \times 10^{-6}\right)$. The 95 th percentile inhalation risk level for $\Sigma_{15} \mathrm{PAHs}$ were usually found greater than the acceptable carcinogenic risk level, except in summer $\left(5.88 \times 10^{-7}\right)$. The mean inhalation risk levels for $\Sigma_{15}$ PAHs estimated in this study are higher than those population inhalation risks reported for several other locations in Turkey (industrial/urban and rural sites in Kutahya, Dumanoglu et al., 2017; a suburban site in Izmir, Ugranli et al., 2016; a small city, Balikesir, Gungormus et al., 2014). These differences could be explained with the densely populated industrial facilities in Dilovasi, and the other parts of Kocaeli. Population probability distributions of carcinogenic risk associated with $\Sigma_{15} \mathrm{PAHs}$ inhalation exposure for each season are given in Fig. 8. Recently, air samples were collected from September 2012 to August 2013 at 176 sites (11 background, 83 rural, and 82 urban) in five Asian countries, including China, Japan, South Korea, Vietnam, and India (Hong et al., 2016). Higher concentrations of PAHs were detected especially in the sites with denser population, traffic congestion, and higher industrial activities. The lifetime inhalation cancer risk due to PAH exposure was investigated by using a unit risk value of $1.1 \times 10^{-6}$ per $\mathrm{ng} / \mathrm{m}^{3}$. The mean cancer risk levels were estimated as 27.8, 1.36, 2.45, 21.8, and $9.10 \times 10^{-6}$ for China, Japan, South Korea, Vietnam, and India, respectively. These levels are greater than those in this study.

The maximum exposure level of $\Sigma_{41}$ PCBs was calculated for summer (mean: 509 pg/kg/day), the lowest level was for winter (mean: 165 $\mathrm{pg} / \mathrm{kg} / \mathrm{day}$, see Table 1 ). The PCB congeners, especially having larger number of chlorine atoms, tend to bioaccumulate in the environment, deposit, and retain close to point of source. The volatilization process from contaminated environmental surfaces to the atmosphere increases with an increase in air temperature (Cetin et al., 2017a; Sofuoglu et al., 2001). Therefore, the highest gaseous concentration and exposure level of $\Sigma_{41}$ PCBs in summer were most probably related to the rise in air temperature. The estimated mean and 95th percentile carcinogenic inhalation risks were in the range of $4.90 \times 10^{-6}$ to $8.24 \times 10^{-6}$, and of $1.09 \times 10^{-5}$ to $1.98 \times 10^{-5}$, respectively. The percentage of the population exceeding the acceptable risk level $\left(10^{-6}\right)$ was greater than $>90 \%$ for each season, while the respective proportion for $10^{-5}$ was $\sim 50 \%$ in autumn, summer, and winter, and $\sim 25 \%$ in spring. Results of this study indicate that majority of the population living in Dilovasi is at significant health risk. The estimation of PCB exposure and health risk have been reported in a limited number of studies in Turkey (Birgül et al., 2017; Dumanoglu et al., 2017; Ugranli et al., 2016). In the study conducted by Dumanoglu et al. (2017), the air $(n=82)$ and soil $(\mathrm{n}=82)$ samples were collected from 41 sites ( 22 industrial/ urban and 19 rural sites) in Kutahya, Turkey, a.k.a the province of thermal power plants, during summer and winter in 2014. The main sources of PCBs were determined as coal combustion in thermal power plants and residential heating, followed by evaporative emissions from previously used technical PCB mixtures. The median population cancer risks of $\Sigma_{41}$ PCBs associated with exposure by the inhalation route were estimated in the range of $3.27 \times 10^{-8}$ (industrial/urban area, summer) $-5.84 \times 10^{-8}$ (rural area, winter). In studies conducted by Ugranli et al. (2016) and Birgül et al. (2017), the estimated inhalation cancer risks were reported in the range of about $7 \times 10^{-8}$ to $2 \times 10^{-7}$ in Bursa and Izmir. Hence, the estimated carcinogenic risk levels in this
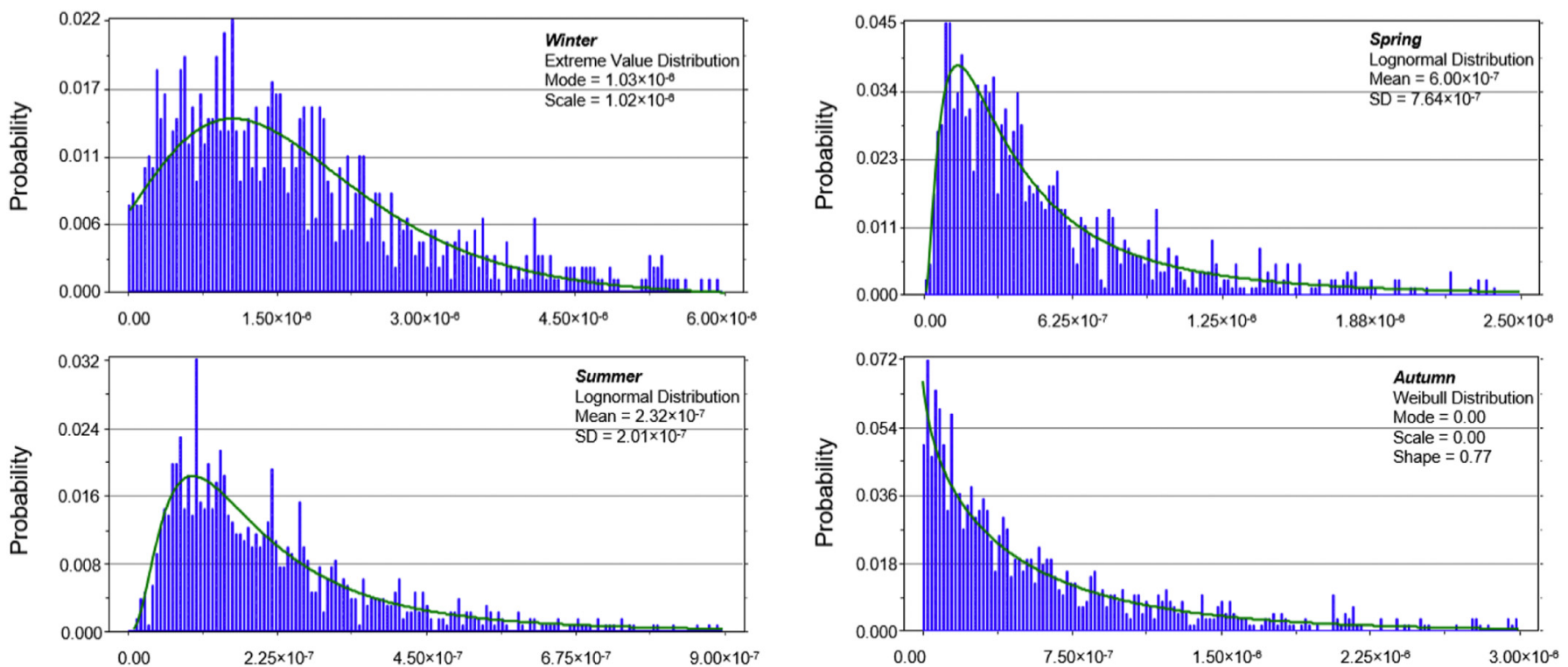

Fig. 8. Population probability distributions of carcinogenic risk associated with inhalation exposure to $\Sigma_{15}$ PAHs for each season. 

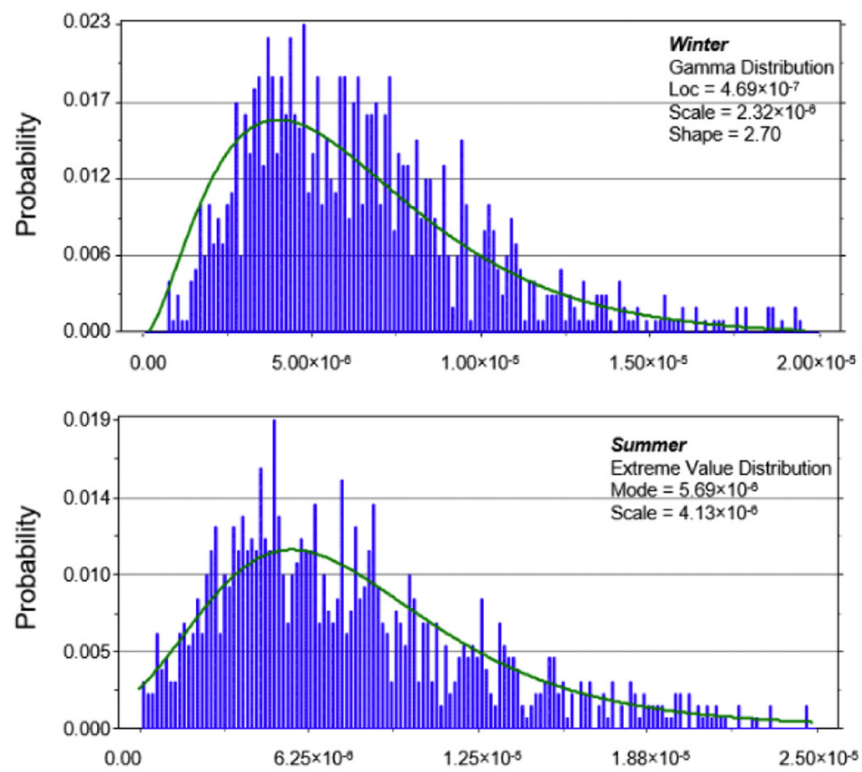
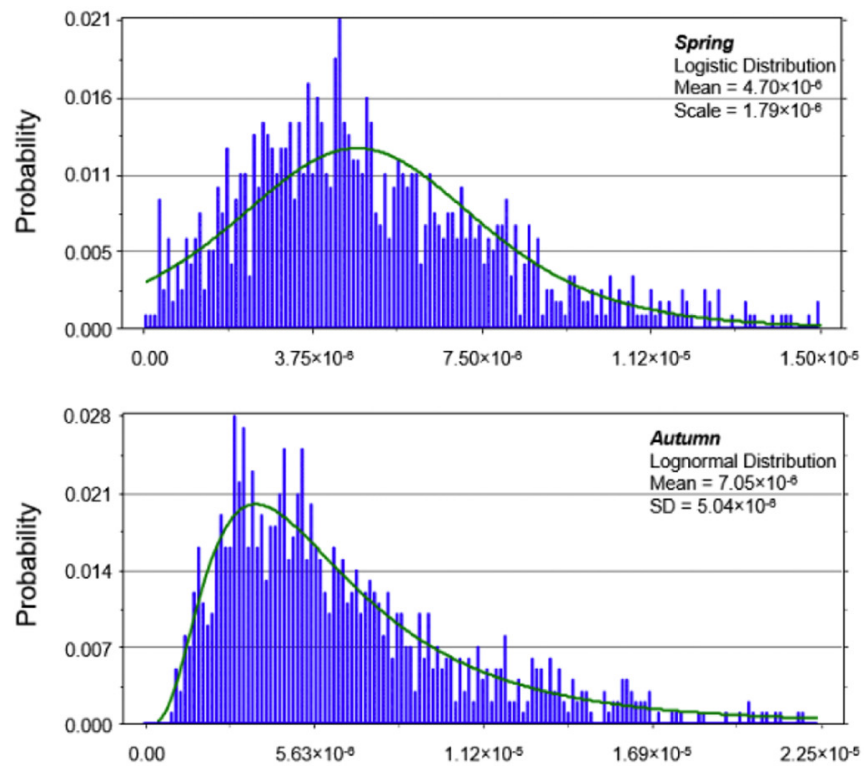

Fig. 9. Population probability distributions of carcinogenic risk associated with inhalation exposure to $\Sigma_{41}$ PCBs for each season.

study are approximately 100 -folds greater than those reported in the previous studies conducted in Turkey. Population probability distributions of carcinogenic risk associated with $\Sigma_{41}$ PCBs inhalation exposure for each season are given in Fig. 9.

In addition, both Dumanoglu et al. (2017) and Ugranli et al. (2016) included both PAHs and PCBs in their risk assessments, reporting higher levels for PAHs compared to PCBs. Differently in this study, carcinogenic risks associated with exposure to PCBs are greater than those of PAHs, and those of reported in the two cited studies. This finding may be related to the presence of several large industries in the study area, especially iron and steel plants that were also found as main sources in PMF results (with $60 \%$ of total variance). There are tens of iron and steel production plants located in Dilovasi and also in Kocaeli. Previously, it was reported that ambient air and soil PCDD/F concentrations measured in the City of Kocaeli were about 10 times higher than those in the rural Kocaeli, and higher than those in the literature measured in various urban areas (Bakoglu et al., 2005). Later on, PCDD/F contamination in animal products (eggs, milk, meat) collected in the province were found to be higher in Dilovasi and the city than the rural area, higher in local samples compared to commercial products, and higher than the limit value of $3 \mathrm{pg}$ TEQ per $\mathrm{g}$ of fat (Aslan et al., 2010). The probable sources for the PCDD/F contamination quoted in the two studies are also probable sources of PCBs, which may explain the higher risks found in this study associated with PCBs compared to PAHs. Consequently, exposure to PCBs is probably an important environmental issue that should be dealt with to mitigate the situation and protect human and environmental health. In addition to PCBs, other pollutants emitted by the

Table 2

Uncertainty in the estimated population exposure to $\Sigma_{15} \mathrm{PAHs}\left(\mathrm{ng} / \mathrm{kg} /\right.$ day) and $\Sigma_{41} \mathrm{PCBs}$ (pg/kg/day).

\begin{tabular}{lllll}
\hline & Statistic & 5th percentile & Mean & 95th percentile \\
\hline$\Sigma_{15}$ PAHs & Minimum & 0.048 & 0.717 & 2.451 \\
& Maximum & 0.075 & 1.065 & 3.907 \\
& Median & 0.060 & 0.859 & 3.072 \\
& Mean & 0.060 & 0.864 & 3.114 \\
$\Sigma_{41}$ PCBs & SD & 0.005 & 0.063 & 0.197 \\
& Minimum & 0.047 & 0.531 & 1.829 \\
& Maximum & 0.058 & 0.668 & 2.563 \\
& Median & 0.053 & 0.592 & 2.200 \\
& Mean & 0.052 & 0.594 & 2.158 \\
& SD & 0.002 & 0.027 & 0.138
\end{tabular}

apportioned sources such as PBDEs and PCNs (Cetin and Odabasi, 2008; Odabasi et al., 2009; 2012), may also be significant issues for Dilovasi.

\subsubsection{Uncertainty analysis}

The uncertainty associated with the Monte Carlo sampling applied in population risk assessment was analyzed for the estimated annual mean, 5th and 95th percentile exposure levels (Table 2). Coefficient of Variability for $\Sigma_{15}$ PAHs and $\Sigma_{41}$ PCBs are $7.3 \%$ and $4.5 \%$ for the mean; $8.3 \%$ and $3.8 \%$ for the 5 th percentile; $6.3 \%$ and $6.4 \%$ for the 95 th percentile, respectively. These levels show that the uncertainties arisen from the Monte Carlo simulation remained low.

\section{Conclusion}

In this study, previously reported ambient air concentrations of PAHs and PCBs were investigated in terms of their possible sources and carcinogenic health risks. At 23 sampling sites, average concentrations were found as $285 \mathrm{ng} \mathrm{m}^{-3}$ and $4152 \mathrm{pg} \mathrm{m}^{-3}$ for $\Sigma_{15} \mathrm{PAH}$ and $\Sigma_{41}$ PCB, respectively. The last version of PMF ( $v$ 5.0), enables users to handle multiple site data, was applied to infer on the sources of PAHs and PCBs. Emissions of diesel and gasoline vehicles, biomass and coal combustion, iron and steel industry, and unburned petroleum/petroleum products were identified as the possible PAHs sources. Additionally, specified PCB sources were iron-steel production, coal and biomass burning, technical PCB mixtures, and industrial emissions. The calculated mean carcinogenic risk levels of PAHs for all sampling points except sampling site 3 and 6 , and the calculated 95th percentile carcinogenic risk levels for all sampling points in Dilovasi were found as $>10^{-6}$ while 95 th percentile was $>10^{-5}$ at 15 out 23 sampling locations. For PCBs, considerable potential health risks were calculated as the mean risk levels for all sampling points were $>10^{-5}$, while they were $>10^{-4}$ at 8 out of 23 locations indicating exposure to $\mathrm{PCBs}$ is probably an important environmental issue. Residential areas in Dilovası are in mesh with the organized industrial zones and main roads, and railways. Thousands of people living in the district are exposed to high $\mathrm{PAH}$ and PCB concentrations, some of whom are employed by these numerous industries $(>20,000)$. Thus, it is crucial that the health impacts of these pollutants should be dealt with to mitigate the situation and protect human and environmental health. In addition to PCBs, other pollutants emitted by the apportioned sources such as PBDEs and PCNs, may also be significant issues for Dilovasi. 


\section{Acknowledgments}

This study was supported by the Scientific and Technological Research Council of Turkey (TUBITAK) with the project number of 113Y500. We would like to thank Mustafa Odabasi (Dokuz Eylul University) for his support.

\section{Appendix A. Supplementary data}

Supplementary data to this article can be found online at https://doi. org/10.1016/j.scitotenv.2018.03.145.

\section{References}

Acara, A., 2006. Türkiye'nin Kalıcı O0rganik Kirletici Maddelere (POP'ler) İlișkin Stockholm Sözleşmesi için Taslak Ulusal Uygulama Planı. Republic of Turkey Ministry of Environment and Forests.

Alsberg, T., Håkansson, S., Strandell, M., Westerholm, R., 1989. Profile analysis of urban air pollution. Chemom. Intell. Lab. Syst. 7, 143e152

Amador-Munoz, O., Villalobos-Pietrini, R., Agapito-Nadales, M.C., Munive-Colin, Z., Hernandez-Mena, L., Sanchez-Sandoval, M., Gomez-Arroyo, S., Bravo-Cabrera, J.L., Guzman-Rincon, J., 2010. Solvent extracted organic matter and polycyclic aromatic hydrocarbons distributed in size-segregated airborne particles in a zone of Mexico City: seasonal behavior and human exposure. Atmos. Environ. 44, 122-130.

Amarillo, A.C., Mateos, A.C., Carreras, H., 2017. Source apportionment of PM10-bound polycyclic aromatic hydrocarbons by positive matrix factorization in Córdoba City, Argentina. Arch. Environ. Contam. Toxicol. 72 (3), 380-390.

Arslan, O., Cepni, M.S., Etiler, N., 2013. Spatial analysis of perinatal mortality rates with geographic information systems in Kocaeli, Turkey. Public Health 127, 369-379.

Aslan, S., Kemal Korucu, M., Karademir, A., Durmusoglu, E., 2010. Levels of PCDD/Fs in local and non-local food samples collected from a highly polluted area in Turkey. Chemosphere 80 (10), 1213-1219.

ATSDR, 2000. Toxicological Profile for Polychlorinated Biphenyls. U.S. Department of Health and Human Services, Public Health Service, Atlanta, GA.

ATSDR, 2009. Toxicity of Polycyclic Aromatic Hydrocarbons (PAHs). Agency for Toxic Substances and Disease Registry, Atlanta, GA: US Department of Health and Human Services.

Aydın, Y.M., Kara, M., Dumanoglu, Y., Odabası, M., Elbir, T., 2014. Source apportionment of polycyclic aromatic hydrocarbons (PAHs) and polychlorinated pıphenyls (PCBs) in ambient air of an industrial region in Turkey. Atmos. Environ. 97, 271-285.

Bakoglu, M., Karademir, A., Durmusoglu, E., 2005. Evaluation of PCDD/F levels in ambient air and soils and estimation of deposition rates in Kocaeli, Turkey. Chemosphere 59 (10), 1373-1385.

Birgül, A., Kurt-Karakus, P.B., Alegria, H., Gungormus, E., Celik, H., Cicek, T., Güven, C., 2017. Polyurethane foam (PUF) disk passive samplers derived polychlorinated biphenyls (PCBs) concentrations in the ambient air of Bursa-Turkey: spatial and temporal variations and health risk assessment. Chemosphere 168, 1345-1355.

Breivik, K., Sweetman, A., Pacyna, J.M., Jones, K.C., 2002. Towards a global historical emission inventory for selected PCB congeners - a mass balance approach 1. Global production and consumption. Sci. Total Environ. 290, 181-198.

Bulejko, P., Adamec, V., Schüllerová, B., Skeřil, R., 2016. Levels, sources, and health risk assessment of polycyclic aromatic hydrocarbons in Brno, Czech Republic: a 5-year study. Environ. Sci. Pollut. Res. 23 (20), 20462-20473.

CalEPA, 2015. Air Toxics Hot Spots Program Guidance Manual for Preparation of Health Risk Assessments. Office of Environmental Health Hazard Assessment, Oakland, CA.

Cetin, B., 2016. Investigation of PAHs, PCBs and PCNs in soils around a heavily industrialized area in Kocaeli, Turkey: concentrations, distributions, sources and potential health risks. Sci. Total Environ. 560-561, 160-169.

Cetin, B., Odabasi, M., 2008. Atmospheric Concentrations and Phase Partitioning of Polybrominated Diphenyl Ethers (PBDEs) in Izmir, Turkey. Chemosphere 71 (6), 1067-1078.

Cetin, B., Yatkin, S., Bayram, A., Odabasi, M., 2007. Ambient concentrations and source apportionment of PCBs and trace elements around an industrial area in Izmir, Turkey. Chemosphere 69, 1267-1277.

Cetin, B., Yurdakul, S., Keles, M., Celik, I., Ozturk, F., Dogan, C., 2017a. Atmospheric concentrations, distributions and air-soil exchange tendencies of PAHs and PCBs in a heavily industrialized area in Kocaeli, Turkey. Chemosphere 183, 69-79.

Cetin, B., Ozturk, F., Keles, M., Yurdakul, S., 2017b. PAHs and PCBs in an Eastern Mediterranean Megacity, Istanbul: their spatial and temporal distributions, air-soil exchange and toxicological effects. Environ. Pollut. 220, 1322-1332.

Cuadras, A., Rovira, E., Marcé, R.M., Borrull, F., 2016. Lung cancer risk by polycyclic aromatic hydrocarbons in a Mediterranean industrialized area. Environ. Sci. Pollut. Res. Int. 23 (22), 23215-23227.

Davies, H., Delistraty, D., 2016. Evaluation of PCB sources and releases for identifying priorities to reduce PCBs in Washington State (USA). Environ. Sci. Pollut. Res. 23 (3), 2033-2041.

Dumanoglu, Y., Gaga, E.O., Gungormus, E., Sofuoglu, S.C., Odabasi, M., 2017. Spatial and seasonal variations, sources, air-soil exchange, and carcinogenic risk assessment for PAHs and PCBs in air and soil of Kutahya, Turkey, the province of thermal power plants. Sci. Total Environ. 580, 920-935.

Gaga, E.O., Ari, A., Döğeroğlu, T., Çakırca, E.E., Machin, N.E., 2012. Atmospheric polycyclic aromatic hydrocarbons in an industrialized city, Kocaeli, Turkey: study of seasonal variations, influence of meteorological parameters and health risk estimation. J. Environ. Monit. 14 (8), 2219-2229.

Gedik, K., Demircioglu, F., Imamoglu, I., 2010. Spatial distribution and source apportionment of PCBs in sediments around İzmit industrial complexes, Turkey. Chemosphere 81, 992-999.

Gungormus, E., Tuncel, S., Tecer, H.L., Sofuoglu, S.C., 2014. Inhalation and dermal exposure to atmospheric polycyclic aromatic hydrocarbons and associated carcinogenic risks in a relatively small city. Ecotoxicol. Environ. Saf. 108, 106-113.

Hong, W.J., Jia, H., Ma, W.L., Sinha, R.K., Moon, H.B., Nakata, H., Minh, N.H., Chi, K.H., Li, W.L., Kannan, K., Sverko, E., Li, Y.F., 2016. Distribution, fate, inhalation exposure and lung cancer risk of atmospheric polycyclic aromatic hydrocarbons in some Asian countries. Environ. Sci. Technol. 50 (13), 7163-7174.

Hu, D., Hornbuckle, K.C., 2010. Inadvertent polychlorinated biphenyls in commercial paint pigments. Environ. Sci. Technol. 15 (44(8)), 2822-2827.

Jang, E., Alam, M.S., Harrison, R.M., 2013. Source apportionment of polycyclic aromatic hydrocarbons in urban air using positive matrix factorization and spatial distribution analysis. Atmos. Environ. 79, 271-285.

Jin, R.H., Park, S.U., Park, J.E., Kim, J.G., 2012. Polychlorinated biphenyl congeners in river sediments: distribution and source identification using multivariate factor analysis. Arch. Environ. Contam. Toxicol. 62, 411-423.

Kavcar, P. Odabasi, M. Kitis, M., Inal, F, Sofuoglu, S.C., 2006. Occurrence, oral exposure and risk assessment of volatile organic compounds in drinking water for Izmir. Water Res. 40 (17), 3219-3230.

Kavcar, P., Sofuoglu, A., Sofuoglu, S.C., 2009. A health risk assessment for exposure to trace metals via drinking water ingestion pathway. Int. J. Hyg. Environ. Health 212 (2), 216-227.

Kavouras, I.G., Koutrakis, P., Tsapakis, M., Lagoudaki, E., Stephanou, E.G., Von Baer, D. Oyola, P., 2001. Source apportionment of urban particulate aliphatic and polynuclear aromatic hydrocarbons (PAHs) using multivariate methods. Environ. Sci. Technol. 35 2288-2294.

Kaya, E., Dumanoglu, Y., Kara, M., Altıok, H., Bayram, A., Elbir, T., Odabașı, M., 2012. Spatial and temporal variation and air-soil exchange of atmospheric PAHs and PCBs in an industrial region. Atmos. Pollut. Res. 3, 435-449.

Kim, K.S., Hirai, Y., Kato, M., Urano, K., Masunaga, S., 2004. Detailed PCB congener petterns in incinerator flue gas and commercial PCB formulations (Kanechlor). Chemosphere $55,539-553$.

KSO, 2016. 2015 Yılı Türkiye'nin 500 Büyük Sanayi Kuruluşu İçerisinde Kocaeli'nde Yerleșik Sanayi Kuruluşlarının Profili. Kocaeli Sanayi Odası, İș Geliștirme Servisi.

Larsen, R.K., Baker, J.E., 2003. Source apportionment of polycyclic aromatic hydrocarbons in the urban atmosphere: a comparison of three methods. Environ. Sci. Technol. 37 1873-1881.

Lee, R.G.M., Coleman, P. Jones, J.L., Jones, K.C. Lohmann, R. 2005. Emission Factors and Importance of PCDD/Fs, PCBs, PCNs, PAHs and $\mathrm{PM}_{10}$ from the Domestic Burning of Coal and Wood in the U.K. Environ. Sci. Technol. 39 (6), 1436-1447.

Li, W., Peng, Y., Shi, J., Qiu, W., Wang, J., Bai, Z., 2011. Particulate polycyclic aromatic hydrocarbons in the urban Northeast Region of China: profiles, distributions and sources. Atmos. Environ. 45, 7664-7671.

Motelay-Massei, A., Ollivon, D., Garban, B., Tiphagne-Larcher, K., Zimmerlin, I., Chevreuil, M., 2007. PAHs in the bulk atmospheric deposition of the Seine river basin: source identification and apportionment by ratios, multivariate statistical techniques and scanning electron microscopy. Chemosphere 67, 312-321.

Nisbet, I.C., LaGoy, P.K., 1992. Toxic equivalency factors (TEFs) for polycyclic aromatic hydrocarbons (PAHs). Regul. Toxicol. Pharmacol. 16, 290-300.

Odabasi, M., Bayram, A., Elbir, T., Seyfioglu, R., Dumanoglu, Y., Bozlaker, A. Demircioglu, H., Altiok, H., Yatkin, S., Cetin, B., 2009. Electric arc furnaces for steel-making: hot spots for persistent organic pollutants. Environ. Sci. Technol. 43, 5205-5211.

Odabasi, M., Bayram, A., Elbir, T., Dumanoglu, Y., Kara, M., Altiok, H., Cetin, B., 2012. Investigation of seasonal variations and sources of atmospheric polychlorinated naphthalenes (PCNs) in an urban area. Atmos. Pollut Res. 3, 477-484.

Odabasi, M., Dumanoglu, Y., Kara, M., Altiok, H., Elbir, T., Bayram, A., 2017. Spatial variation of PAHs and PCBs in coastal air, seawater, and sediments in a heavily industrialized region. Environ. Sci. Pollut. Res. 24 (15), 13749-13759.

Ogulmus, R., Tasdemir, Y., Cindoruk, S.S., 2016. Polychlorinated biphenyl (PCB) levels in soils near wastewater treatment plants and landfills. Ekoloji 25 (98), 1-8.

Polissar, A.V., Hopke, P.K., Poirot, R.L., 2001. Atmospheric aerosol over Vermont: chemical composition and sources. Environ. Sci. Technol. 35, 4604-4621.

Rajput, N., Lakhani, A., 2010. Measurements of polycyclic aromatic hydrocarbons in an urban atmosphere of Agra, India. Atmosfera 23, 165-183.

Ravindra, K., Grieken, S.R.V., 2008. Atmospheric polycyclic aromatic hydrocarbons: source attribution, emission factors and regulation. Atmos. Environ. 42, 2895-2921.

Sadiktsis, I., Bergvall, C., Johansson, C., Westerholm, R., 2012. Automobile tires-a potential source of highly carcinogenic dibenzopyrenes to the environment. Environ. Sci. Technol. 46, 3326-3334.

Shoeib, M., Harner, T., 2002. Characterization and comparison of three passive air samplers for persistent organic pollutants. Environ. Sci. Technol. 36 $4142-4151$.

Sofuoglu, A., Odabasi, M., Tasdemir, Y., Khalili, N.R., Holsen, T.M., 2001. Temperature dependence of gas-phase polycyclic aromatic hydrocarbon and organochlorine pesticide concentrations in Chicago air. Atmos. Environ. 35 (36), 6503-6510.

Sofuoglu, S.C., Güzelkaya, H., Akgül, Ö., Kavcar, P., Kurucaovalı, F., Sofuoglu, A., 2014 Speciated arsenic concentrations, exposure, and associated health risks for rice and bulgur. Food Chem. Toxicol. 64, 184-191.

Takasuga, T., Senthilkumar, K., Matsumura, T., Shiozaki, K., Sakai, S.I., 2006. Isotope dilution analysis of polychlorinated biphenyls (PCBs) in transformer oil and global 
commercial PCB formulations by high resolution gas chromatography-high resolution mass spectrometry. Chemosphere 62, 469-484.

Ugranli, T., Gungormus, E., Kavcar, P., Demircioglu, E., Odabasi, M., Sofuoglu, S.C., Lammel, G., Sofuoglu, A., 2016. POPs in a major conurbation in Turkey: ambient air concentrations, seasonal variation, inhalation and dermal exposure, and associated carcinogenic risks. Environ. Sci. Pollut. Res. 23 (22), 22500-22512.

USEPA, 1996. PCBs: Cancer Dose-Response Assessment and Application to Environmental Mixtures. US Environmental Protection Agency, Washington, DC.

USEPA, 1997. Exposure Factors Handbook. Office of Research and Development, Nationa Center for Environmental Assessment, US Environmental Protection Agency, Washington, DC.

USEPA, 2005. Guidelines for Carcinogen Risk Assessment, Risk Assessment Forum. US Environmental Protection Agency, Washington, DC.

USEPA, 2007. Slope Factors (SF) for Carcinogens. US Environmental Protection Agency, Washington, DC

USEPA, 2010. Development of a Relative Potency Factor (RPF) Approach for Polycyclic Aromatic Hydrocarbon (PAH) Mixtures (External Review Draft). US Environmental Protection Agency, Washington, DC.

USEPA, 2011. Exposure Factors Handbook, EPA/600/R-090/052F. Office of Research and Development National Center for Environmental Assessment. US Environmental Protection Agency, Washington, DC.

USEPA, 2014. Positive Matrix Factorization (PMF) 5.0, fundamentals and user guide. https://www.epa.gov/sites/production/files/2015-02/documents/pmf_5.0_user_ guide.pdf, Accessed date: December 2017.

Vilavert, L., Nadal, M., Schuhmacher, M., Domingo, J.L., 2014. Seasonal surveillance of airborne PCDD/Fs, PCBs and PCNs using passive samplers to assess human health risks. Sci. Total Environ. 466, 733-740.
Wang, C., Wu, S., Zhou, S.L., Wang, H., Li, B., Chen, H., Yu, Y., Shi, Y., 2015. Polycyclic aromatic hydrocarbons in soils from urban to rural areas in Nanjing: concentration, source, spatial distribution, and potential human health risk. Sci. Total Environ. 527-528, 375-383.

Wild, S.R., Jones, K.C., 1995. Polynuclear aromatic hydrocarbons in the United Kingdom environment: a preliminary source inventory and budget. Environ. Pollut. 88, 91-108.

Yilmaz Civan, M. 2010. Spatial Distribution of Organic Pollutants in Bursa Atmosphere: Seasonality and Health Effects. Environmental Engineering, Middle East Technical University (Thesis).

Yılmaz Civan, M., Elbir, T., Seyfioglu, T., Kuntasal, O.O., Bayram, A., Dogan, G., Yurdakul, S., Andic, O., Muezzinoglu, A., Sofuoglu, S.C., et al., 2015. Spatial and temporal variations in atmospheric $\mathrm{VOCs}, \mathrm{NO}_{2}, \mathrm{SO}_{2}$, and $\mathrm{O}_{3}$ derişims at a heavily industrialized region in Western Turkey, and assessment of the carcinogenic risk levels of benzene. Atmos. Environ. 103, 102-113.

Zhang, L., Dong, L., Yang, W., Zhou, L., Shi, S., Zhang, X., Niu, S., Li, L., Wu, Z., Huang, Y., 2013. Passive air sampling of organochlorine pesticides and polychlorinated biphenyls in the Yangtze River Delta, China: concentrations, distributions, and cancer risk assessment. Environ. Pollut. 181, 159-166.

Zhuo, S., Shen, G., Zhu, Y., Du, W., Pan, X., Li, T., Han, Y., Li, B., Liu, J., Cheng, H., Xing, B., Tao, S., 2017. Source-oriented risk assessment of inhalation exposure to ambient polycyclic aromatic hydrocarbons and contributions of non-priority isomers in urban Nanjing, a megacity located in Yangtze River Delta, China. Environ. Pollut. 224, 796-809.

Zuo, Q., Duan, Y.H., Yang, Y., Wang, X.J., Tao, S., 2007. Source apportionment of polycyclic aromatic hydrocarbons in surface soil in Tianjin, China. Environ. Pollut. 147, 303-310. 